\title{
A REVIEW OF THE CTOA/CTOD FRACTURE CRITERION - WHY IT WORKS!
}

\author{
J. C. Newman, Jr. and M. A. James ${ }^{\dagger}$ \\ NASA Langley Research Center \\ Hampton, Virginia 23681-2199
}

\begin{abstract}
The CTOA/CTOD fracture criterion is one of the oldest fracture criteria applied to fracture of metallic materials with cracks. During the past two decades, the use of elastic-plastic finite-element analyses to simulate fracture of laboratory specimens and structural components using the CTOA criterion has expanded rapidly. But the early applications were restricted to two-dimensional analyses, assuming either plane-stress or plane-strain behavior, which lead to generally nonconstant values of CTOA, especially in the early stages of crack extension. Later, the non-constant CTOA values were traced to inappropriate state-of-stress (or constraint) assumptions in the crack-front region and severe crack tunneling in thin-sheet materials. More recently, the CTOA fracture criterion has been used with three-dimensional analyses to study constraint effects, crack tunneling, and the fracture process. The constant CTOA criterion (from crack initiation to failure) has been successfully applied to numerous structural applications, such as aircraft fuselages and pipelines. But why does the "constant CTOA" fracture criterion work so well? This paper reviews the results from several studies, discusses the issues of why CTOA works, and discusses its limitations.
\end{abstract}

\section{Introduction}

In the past, the phenomenon of stable crack growth in metallic materials under mode I (tensile) loading has been studied extensively using elastic-plastic finiteelement methods (e.g., Refs. 1-6). These studies were conducted to develop efficient techniques to simulate crack extension and to study various local and global fracture criteria. Some of these criteria were crack-tip stress or strain, crack-tip-opening displacement or angle, crack-tip force, energy-release rates, J-integral, and the tearing modulus. Of these, the critical cracktip-opening angle (CTOA, $\psi_{\mathrm{c}}$ ) or displacement (CTOD) at a specified distance from the crack tip was shown to be the most suited for modeling stable crack growth and instability during the fracture process (e.g., Refs. 3-8). However, some discrepancies among the various analyses have been observed at initiation of stable crack

\footnotetext{
* Senior Scientist, Mechanics and Durability Branch $\dagger$ National Research Council Associate, Mechanics and Durability Branch
}

growth. Early results from de Koning ${ }^{2}$ showed that CTOA was nearly constant from initiation. But Shih et al. ${ }^{3}$, Kanninen et al. ${ }^{4}$, Brocks and Yuan ${ }^{6}$, and Newman et al. ${ }^{7}$ using two-dimensional finite-element analyses (plane stress or plane strain), showed that CTOA at initiation was larger, and in some cases much larger, than the value needed for stable crack growth, as shown in Fig. 1. These results were obtained by matching the finite-element analyses with measurements made of load against crack extension or remote displacement against crack extension. Using the second procedure, Brocks and Yuan ${ }^{6}$ showed that the critical CTOA for a thick aluminum alloy was higher near crack initiation but was roughly constant during stable tearing. For a thinner aluminum alloy ${ }^{8}$, the solid symbols show the high CTOA values near crack initiation, but the values approach nearly a constant after about one thickness of crack extension.

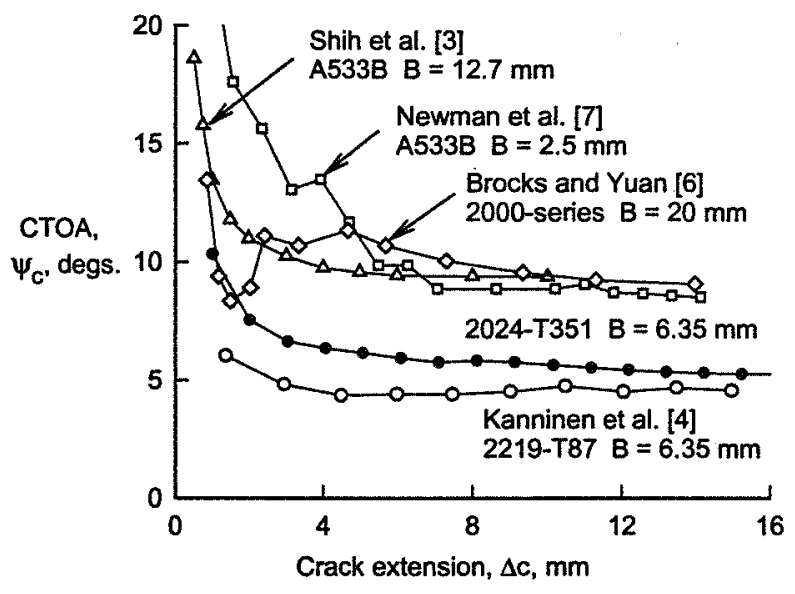

Fig. 1 - Calculated critical CTOA values of various materials using elastic-plastic finite-element analyses.

In spite of the non-constant CTOA values shown by these early studies, Newman ${ }^{5}$ used a constant CTOD (or CTOA) from compact specimens to model crack initiation, stable crack growth and instability. These critical values were then used to predict failure loads on two other crack configurations within $5 \%$ of the test loads for two aluminum alloys and within $10 \%$ of test loads for a very ductile steel. Other researchers have also found that, for various materials and thicknesses, CTOD or CTOA was nearly constant after a small amount of crack extension using two-dimensional finiteelement analyses. 
Later, the non-constant CTOA (or CTOD) values in the early stages of crack extension were traced to inappropriate state-of-stress (or constraint) assumptions in the crack-front region ${ }^{9}$ and severe crack tunneling in thin-sheet aluminum alloy materiais ${ }^{10}$. More recently, the CTOA criterion has been used with threedimensional analyses ${ }^{11-13}$ to study constraint effects, crack tunneling, and the fracture process. The constant CTOA criterion has also been successfully applied to numerous structural applications, such as aircraft fuselages ${ }^{14}$, complex structures ${ }^{15}$, and pipelines ${ }^{16}$. But why does the "constant CTOA" fracture criterion work so well? This paper will review the results from several of these studies, discuss the issues of why CTOA works, and discuss its limitations.

\section{Measurements of CTOA}

Numerous investigators have experimentally measured CTOD or CTOA during the fracture process. Luxmoore et al. ${ }^{17}$ have experimentally shown that CTOA (or CTOD) was constant from the onset of stable crack growth in two aluminum alloys, but have found different values for different crack configurations. These results show the necessity for studying different crack configurations when assessing the validity of any fracture criteria. Paleebut ${ }^{18}$ measured CTOD at the initiation of stable tearing in compact specimens made of two aluminum alloys; and these results agreed well with numerical values (see Ref. 5) obtained on the same materials. Reuter et al. ${ }^{19}$ measured CTOD, using microtopography, at the initial crack front location and found a nearly linear relation with crack extension for low-strength steel. These results imply that CTOA was nearly constant from initiation.

Dawicke et al. ${ }^{11,20}$, using a high-resolution photographic camera with a video system, has shown that the critical CTOA values during stable crack growth (see Fig. 2) in a thin-sheet aluminum alloy were nearly constant after a small amount of tearing. The critical CTOA values measured on thin-sheet aluminum alloy for both middle-crack tension $M(T)$ and compact $\mathrm{C}(\mathrm{T})$ specimens is shown in Fig. 3 as a function of

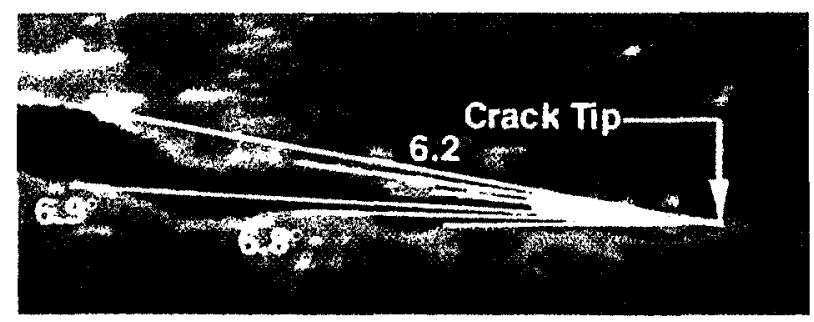

Fig. 2 - Video image of stably tearing crack in a thinsheet aluminum alloy. surface measured crack extension, $\Delta \mathrm{c}_{\mathrm{s}}$. The $\mathrm{C}(\mathrm{T})$ specimen is primarily a bend specimen and the results show that both tension and bend specimens produce nearly the same critical CTOA after a small amount of crack extension. The non-constant CTOA region (measured at the free surface) has been shown to be associated with severe tunneling during the initiation of stable tearing. Dawicke and Sutton ${ }^{20}$ have also compared the high-resolution photographic method and a digital-imaging correlation method to measure the surface CTOA values. These two methods gave very similar CTOA values for thin-sheet aluminum alloys.

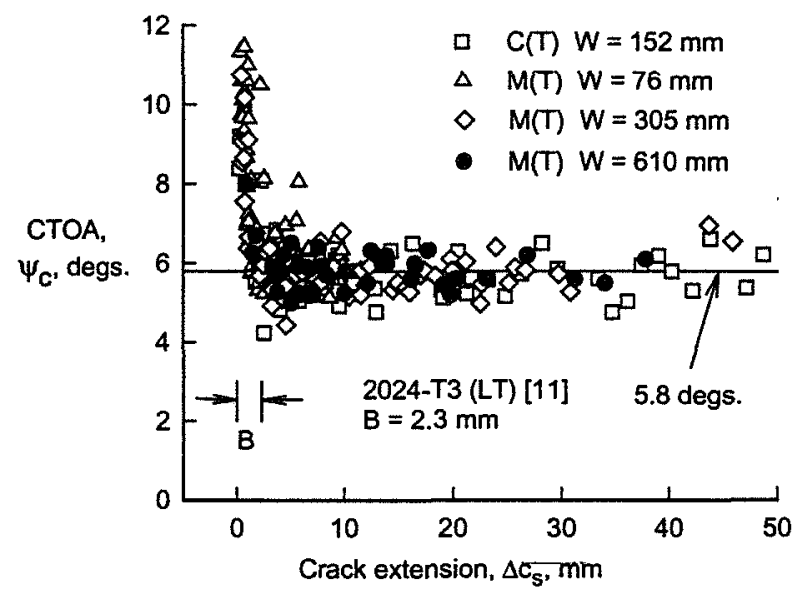

Fig. 3 - Measured critical CTOA values from thin-sheet aluminum alloy specimens.

More recently, Mahmoud and Lease ${ }^{21}$ used these two experimental methods (optical and digital imaging) to measure surface CTOA values on 2024-T351 aluminum alloy from 2 to $25 \mathrm{~mm}$ thick. Their results also showed that CTOA was nearly constant after a small amount of crack extension over a wide range in thickness. The non-constant CTOA region and the scatter in measured CTOA values became smaller for thicker specimens, as shown in Fig. 4.

The measured critical CTOA values for a given material thickness has been shown to be independent of in-plane configuration and loading. These measurements have been made on configurations where the crack length, $c$, and uncracked ligament, $b$, have been large compared to thickness, B. But the critical CTOA is a function of absolute material thickness and the crack-front constraint. Three-dimensional, elasticplastic finite-element analyses have been used to calculate a global constraint factor, $\alpha_{g}$, for a stationary or moving crack front in finite-thickness bodies. The constant CTOA measurements made on various specimen types appear to correspond to the same global constraint factor, as long as the crack length or 
uncracked ligament is greater than or equal to about 4 times the thickness. These results are discussed later.

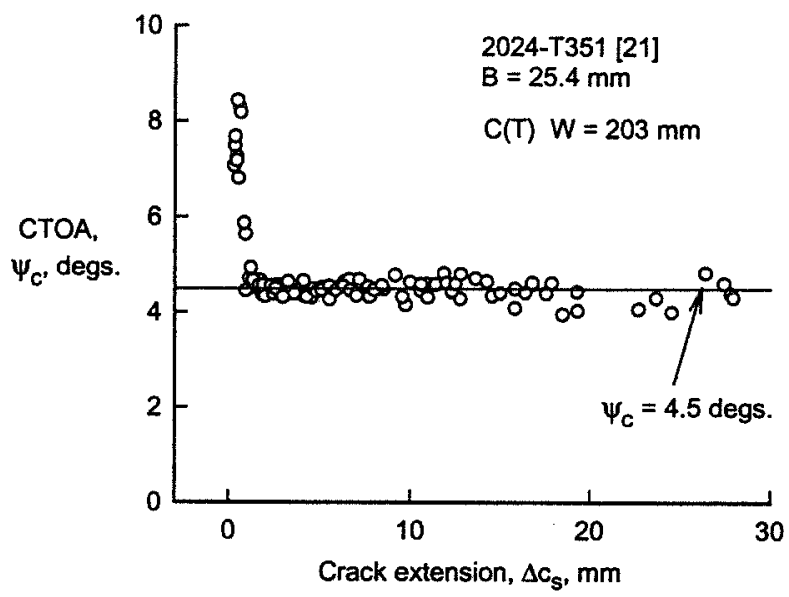

Fig. 4 - Measured critical CTOA values from a thickplate aluminum alloy compact specimens.

\section{Finite-Element Analyses}

Some of the problems associated with the early finiteelement analyses using the CTOD/CTOA fracture criterion, such as the large values of CTOA at crack initiation found by Shih et al. ${ }^{3}$, Kanninen et al. ${ }^{4}$, and others ${ }^{6.7}$ were traced to using either plane-stress or plane-strain conditions around the crack tip and severe tunneling in the thin-sheet materials. Newman et al. ${ }^{9}$ and Dawicke et al. ${ }^{22}$, using two-dimensional analyses with a plane-strain core, and Dawicke et al. ${ }^{11}$ and Gullerud et al. ${ }^{13}$, using three-dimensional analyses, demonstrated that the fracture process for both thin and thick materials is three dimensional and that proper constraint effects must be modeled around the crack front to obtain accurate failure predictions using the constant critical CTOA value. More recently, Young et al. $^{14}$ and Seshadri et al. ${ }^{15}$ successfully used a finiteelement shell code (STAGS ${ }^{23}$ ) and the CTOA failure criterion with the plane-strain core to predict failure of complex structural configurations made of thin-sheet aluminum alloys. These configurations had either single or multiple cracks in flat or curved stiffened panels that failed with severe out-of-plane deformations.

\section{Two-Dimensional Analvses}

In the past, two-dimensional (2-D) elastic-plastic finiteelement analyses, under plane-stress or plane-strain conditions, were used to study stable tearing in various materials. The results indicated that CTOA was high at crack initiation and dropped with crack extension. The results were discouraging and indicated that CTOA was not a constant. However, Newman et al. ${ }^{9}$ found that neither plane-stress nor plane-strain conditions was able to fit experimental test data (25-mm thick steel) using the critical CTOD fracture criterion (equivalent to the CTOA criterion). But a hybrid analysis with a core of plane-strain elements around the crack tip and planestress elements elsewhere was able to fit the test data quite well.

The influence of the state-of-stress on fracture is illustrated in Fig. 5. Fracture results from various width middle-crack tension specimens (restrained from buckling) are shown as symbols ${ }^{24}$. The failure stress is plotted against specimen width for $2 c_{i} / W=1 / 3$. Using a 2-D elastic-plastic, finite-element analysis, a critical angle $\left(\psi_{c}\right)$ of 4.7 degrees with a plane-strain core of 1.9 $\mathrm{mm}$ was determined, by trial-and-error, to best fit the data (solid curve). The plane-strain core half-height $\left(h_{c}\right)$ is measured from the crack plane to the height of the core. Elements within this core had plane-strain conditions. The upper dashed curve shows calculations made with all plane-stress elements with $\Psi_{c}=4.7$ degrees. The shape of the curve is such that it would not be able to fit the failure stresses on all of the specimens. Likewise, the lower dashed curve is the results from plane-strain analyses. Here the analyses fit the smaller specimens but under predicts the failure stresses on the larger specimens. Thus, the fracture process is a 3-D problem and the "plane-strain core" concept allows 2-D analyses to accurately simulate the fracture process. The plane-strain core $\left(h_{c}\right.$ about equal to the thickness) models the high constraint around a crack tip but allows for the widespread plastic yielding under plane-stress conditions away from the crack tip.

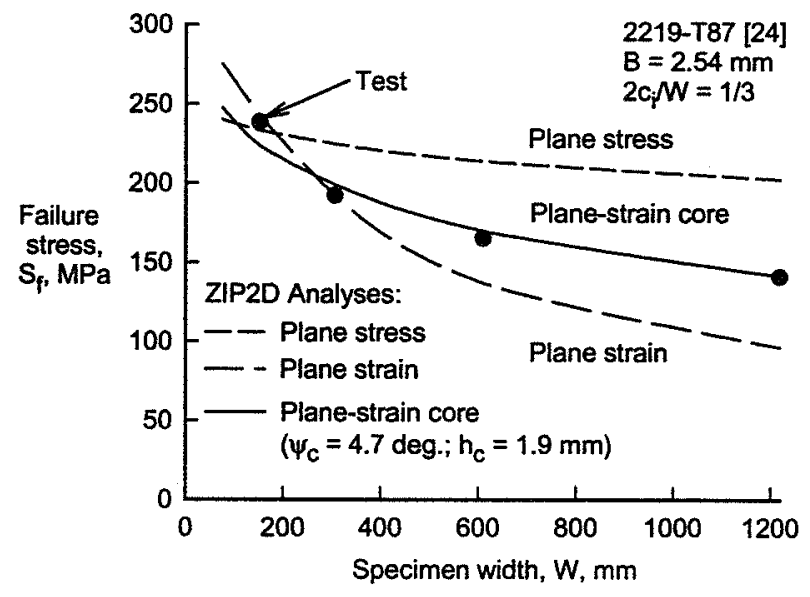

Fig. 5 - Measured and calculated failure stresses for $M(T)$ specimens as a function of specimen width.

\section{Three-Dimensional Analyses}

Although 2-D finite-element codes have been able to fit the failure stresses for various width specimens using the "plane-strain core" concept, the fracture process is three dimensional. Figure 6 illustrates how a 3-D code, 
ZIP3D ${ }^{25}$, can simulate fracture without resorting to an additional parameter, like the plane-strain core. The critical CTOA value of 5.25 degrees was determined from compact specimens ${ }^{12}$. This value was then used to predict the failure stresses on various width $M(T)$ specimens with an initial crack-length-to-width ratio $\left(2 c_{i} / W\right)$ of $1 / 3$. The predicted failure stresses were within a few percent of the measured failure stresses on specimens ranging in width from 30 to $610 \mathrm{~mm}$. Again, 2-D analyses were also performed to illustrate the inadequate behavior predicted by either plane-stress or plane-strain analyses. As shown in Fig. 5, the 2-D analyses were unable to predict the fracture behavior of the wide range in specimen widths. The difference between plane-stress and plane-strain predictions became larger for wider specimens. In the 3-D analyses, the crack was modeled as a flat, straightthrough crack, like that for a 2-D analysis. But, the primary difference between the 2-D and 3-D analyses is the ability of the 3-D analyses to capture the local stress triaxiality near the crack front, while modeling planestress deformations away from the crack.

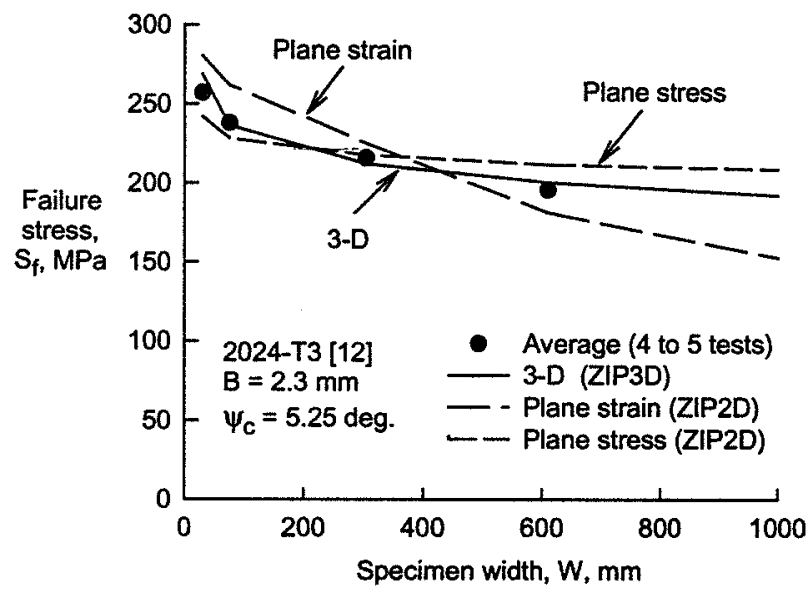

Fig. 6 - Measured and calculated failure stresses for different state-of-stress conditions.

Figure 7 shows the measured and calculated loadagainst-crack extension behavior for the $610-\mathrm{mm}$ wide $M(T)$ specimens from Fig. 6. The applied stress is plotted against crack extension, $\Delta c_{s}$, measured on the free surface. Both 2-D and 3-D analyses tend to over predict crack extension in the early stages of stable tearing. But the 3-D analysis was able to accurately match crack-extension behavior for the remainder of the test. A 2-D analysis ${ }^{26}$ with the plane-strain core (not shown) agreed well with the 3-D analysis from crack initiation to well beyond the maximum load. The discrepancy between the tests and analyses in the early stages of crack extension has been intensely studied in the last decade. It has been observed ${ }^{10,20}$ that severe crack tunneling occurs in the early stages of stable tearing for thin-sheet aluminum alloys. But, is the analysis over predicting crack extension or is the measured crack extension on the free surface under estimating the true damage?

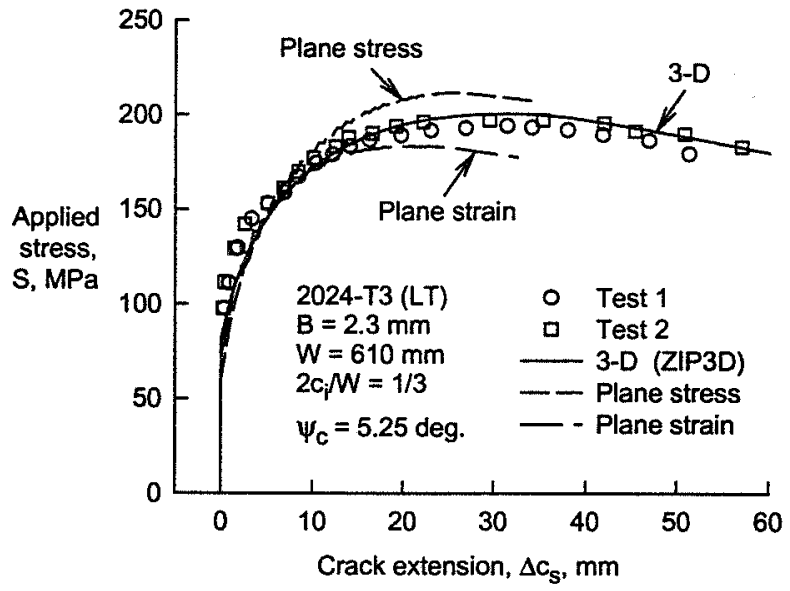

Fig. 7 - Measured and calculated applied stress against crack extension for different state-of-stress conditions.

\section{Crack Tunneling and Analyses}

Fatigue-crack growth tests conducted on thin-sheet aluminum alloys produce crack fronts that are only slightly tunneled. But during a fracture test, the crack front severely tunnels in the interior of the specimen, presumably due to the high (plane-strain) constraint. But the crack front lags at the free surface because of low (plane-stress) constraint conditions. Tunneling can be very severe in the early stages of stable tearing, with tunneling on the order of the sheet thickness or more ${ }^{20}$. Once a crack front goes from flat fracture to shear-mode fracture (fracture surface 45 degrees through the thickness), the crack front tends to straighten out with only slight tunneling. This behavior is characteristic of 2024-T3 aluminum alloy sheet in the LT-orientation (crack perpendicular to rolling direction). However, for the 2024-T3 alloy in the TL-orientation ", the crack surfaces always remained flat (no shear-mode fracture) and the crack tore with a severe tunnel, as shown in Fig. 8(a).

Dawicke et al. " used the three-dimensional, elastic-plastic, finite-element analysis code (ZIP3D) to model crack tunneling during the fracture of the 2024T3 alloy in the TL-orientation. A large number of fracture tests were conducted to determine the amount of crack extension and tunneling (crack-front shape) at a given applied stress. A finite-element mesh was then constructed with five layers of elements through the half thickness. The smaller element thicknesses were placed near the free surface of the specimen. The crack-front 
shapes (element nodes through the thickness) were adjusted to match, as close as possible, the actual crackfront shapes observed in the tests. For each crack-front shape, an applied stress was assigned based on the measured load-surface-crack extension test results. During the fracture simulation, stable crack growth was simulated by allowing the crack to grow when the applied stress reached the predetermined levels. In the simulation, the entire crack front was allowed to advance one node when the applied stress reached the predetermined value corresponding to the current crack length at the surface. The displacements of the nodes behind the crack front on the crack plane were monitored to calculate the crack-tip-opening angle (CTOA). These results are shown in Fig. 8(b).

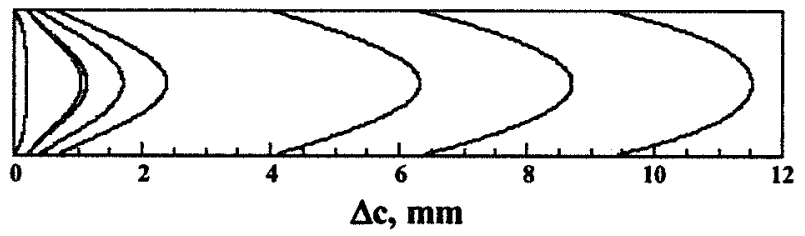

(a) Measured crack-front shapes.

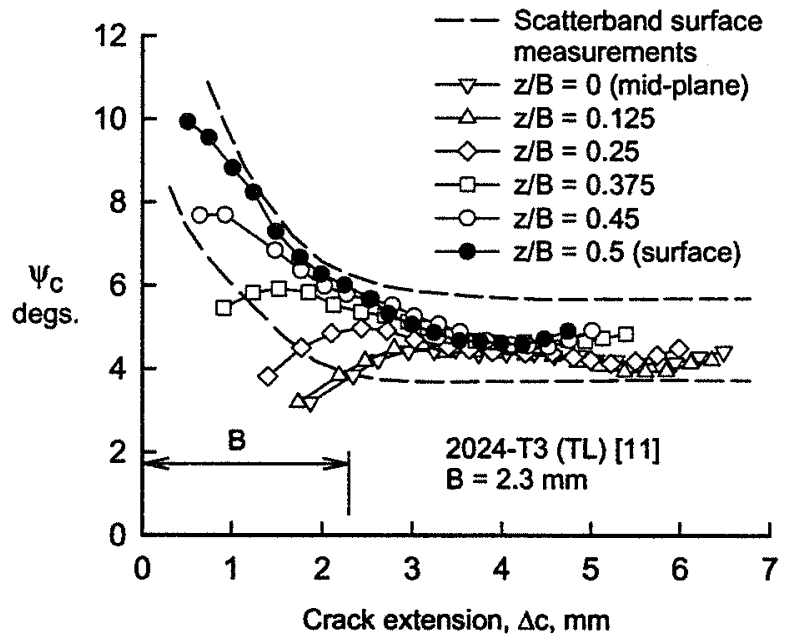

(b) Computed CTOA values.

Fig. 8 - Three-dimensional fracture simulation of crack tunneling and determination of critical CTOA.

The dashed curves in Fig. 8(b) show scatter-bands on experimental measurements made at the free surface of the specimens using the high-resolution photographic method ${ }^{20}$. The symbols show CTOA values calculated at the free surface $(z / B=0.5)$, at different locations through-the-thickness, and at the mid-plane location $(\mathrm{z} / \mathrm{B}=0)$. The tunneled crack-front simulation exhibited a considerable variation in CTOA throughthe-thickness during the initial 3-mm of crack extension at the specimen surface. The surface CTOA values agreed well with the surface measurements. The calculated CTOA values decreased through-thethickness to a value of about 3 degrees at the mid-plane. After $3 \mathrm{~mm}$ of crack extension at the free surface, all through-the-thickness calculations of CTOA approached an average value of about 4.5 degrees, which was the value measured at the free surface.

The results shown in Fig. 8(b) suggest that the high constraint in the interior of the specimen cause a low critical angle and that the low constraint on the free surface causes a high critical angle. When using either 2-D or 3-D finite-element analyses with an assumed straight through-the-thickness crack, what value of critical CTOA should be used in the early stages of crack extension? An engineering approach would be to assume a constant angle, such as 4.5 degrees. This may be a reasonable average value through-the-thickness and may be the reason why the constant CTOA fracture criterion has been so successful. Conversely, when a crack is tunneling, what crack length approximates the average length of the tunneled crack?

James and Newman ${ }^{27}$ have continued to study crack tunneling in a thicker aluminum alloy (2024$\mathrm{T} 351 ; \mathrm{B}=6.35 \mathrm{~mm}$ ) to determine an effective crack extension measure. There are, at least, three measures of crack extension that can be compared with either 2-D or 3-D (straight-through crack) finite-element fracture simulations. They are free-surface values, unloading compliance values, and area-average values. Figure 9 shows measurements made on a large compact specimen, where the crack remained flat and severely tunneled during the complete test, like that shown in Fig. 8(b). The solid and open symbols show free surface and area-average crack-extension measurements, respectively.

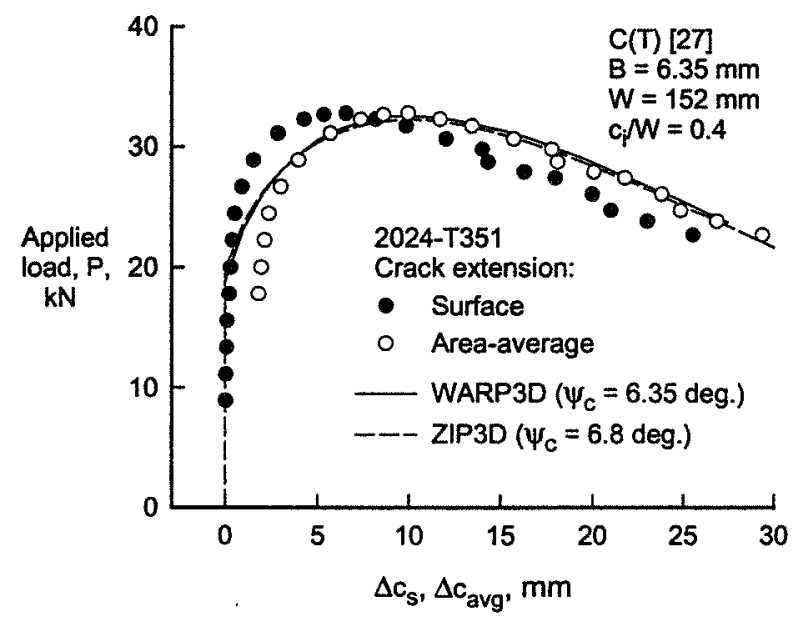

Fig. 9 - Measured and calculated load against crack extension using two measures of crack extension. 
The area-average values were determined from a calibration derived from multiple specimen tests. The solid and dashed curves show 3-D finite-element analyses made with WARP3D ${ }^{28}$ and ZIP3D ${ }^{25}$, respectively. The different critical angles are due to WARP3D being a large-strain code and ZIP3D being a small-strain code. But the analyses agree quite well with each other from crack initiation to large amounts of crack extension. As usual, the comparison with the free surface measured crack-extension values tended to show that either the analyses were over estimating crack extension or the surface measurements were under estimating the crack-front damage. Using the areaaverage values tended to over correct crack extension in the early stages but agree quite well with the analyses at maximum load and to large amounts of crack extension. Thus, the dilemma is, again, associated with crack extension in the early stages, where the fracture process is truly three-dimensional. Three-dimensional fracture simulations, with crack tunneling, would now be required to fit both the surface and interior measured crack-extension values. But, from an engineering standpoint, the use of a constant CTOA concept to average the surface and interior crack-extension values in the initial stages of crack extension may be reasonable.

But James et al. ${ }^{8}$ made an interesting observation about a comparison between 3-D finite-element analyses and measurements made of $\delta_{5}$-displacements during these tests. These results are shown in Fig. 10. The $\delta_{5}$-displacements are measured at the original crack-tip location using a 5-mm gage length, as shown

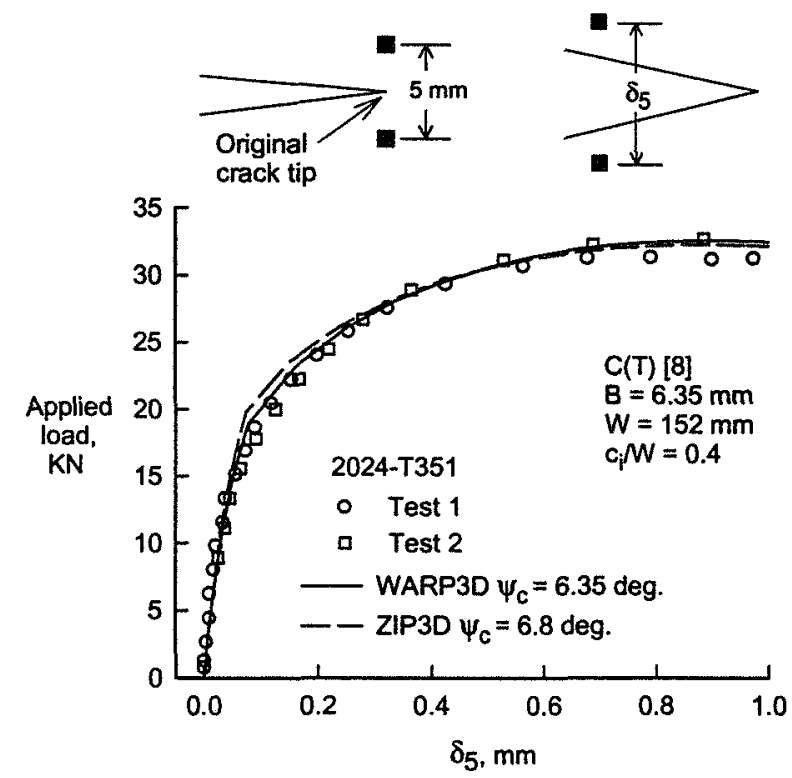

Fig. 10 - Measured and predicted applied load against $\delta_{5}$-displacement. by the insert in Fig. 10. Symbols show measurements made on two compact specimens and the curves show predictions from the two finite-element codes. The displacements measured at the crack-tip location during fracture should be very sensitive to crack tunneling. Whereas, the calculated load-against-crack extension results (Fig. 9) disagreed in the early stages of crack extension, the comparisons between the measured and predicted load-against- $\delta_{5}$ displacements agreed quite well. The large-strain code fit the results slightly better than the small-strain code. (In Ref. 8, measured and predicted load-against- $\delta_{5}$ displacements made on large middle-crack tension specimens using the same critical CTOA values also agreed very well.) These results suggest that the 3-D analyses, with straight-through cracks, are capturing the essence of the 3-D fracture process on the average. Because the constant CTOA concept fit the $\delta_{5}$-displacements quite well, the analyses must be following "effective" crack-extension values as the crack tunnels. The 3-D analyses must also be capturing the constraint variations to match the elasticplastic displacement measurements.

Returning to the results shown in Fig. 1, if the original finite-element fracture simulations had been made with 3-D analyses and had been fitted to loadagainst- $\delta_{5}$ displacements, then more constant values of CTOA may have been calculated. Whether this behavior applies in general, must await further comparisons. But these results lend support to a constant critical CTOA fracture criterion, at least, for the aluminum alloys over a certain range of crack length and thickness.

\section{Constraint Effects}

The results shown in Fig. 3 show that the critical CTOA values, measured at the free surface, approach nearly a constant value after a small amount of crack extension and that the value of CTOA is independent of specimen type. A bend specimen, $C(T)$, and tension specimens, $M(T)$, of various size gave essentially the same results. It was expected that the $C(T)$ specimen would have higher constraint than the $\mathrm{M}(\mathrm{T})$ specimen and result in a lower critical CTOA value for the bend specimen.

In an effort to explain these results, Newman et al. $^{29}$ conducted 3-D elastic-plastic, finite-element calculations on various specimen types over a wide range of configuration parameters. From this study a global constraint factor, $\alpha_{\mathrm{g}}$, was developed. The global constraint factor was an averaged-normal-stress-to flowstress ratio over the plastic region. Because the global constraint factors were found to be nearly independent of specimen type for the thinner materials at the same stress-intensity factor, it was suspected that the cracklength-to-thickness ratio (c/B) and uncracked-ligament- 
length-to-thickness ratio (b/B) were the controlling parameters. The constraint factors for all numerical results where $\mathrm{c} / \mathrm{B}$ and $\mathrm{b} / \mathrm{B}$ ratios are equal to or greater than 4 are shown in Fig. 11. The constraint factor is plotted against a normalized stress-intensity factor, $\mathrm{K} /\left(\sigma_{\mathrm{o}} \sqrt{\mathrm{B}}\right)$, that is proportional to the plastic-zone-tothickness ratio. Plotting in this way, the results for all specimen types, loading, thicknesses, widths, and cracklength-to-width ratios collapsed onto nearly a single curve. The upper dashed lines show the limiting results from plane-strain analyses of the three specimen types. The plane-strain solutions are slightly dependent upon specimen type at low normalized stress-intensity factors. The lower limit appears to be about 1.15 and is nearly independent of specimen type. Results from the $M(T)$ specimens tended to suddenly drop towards unity when the yield region extended across the uncracked ligament. The curves are equations fit to the numerical results for bend and tension specimens that approach the upper plane-strain limit.

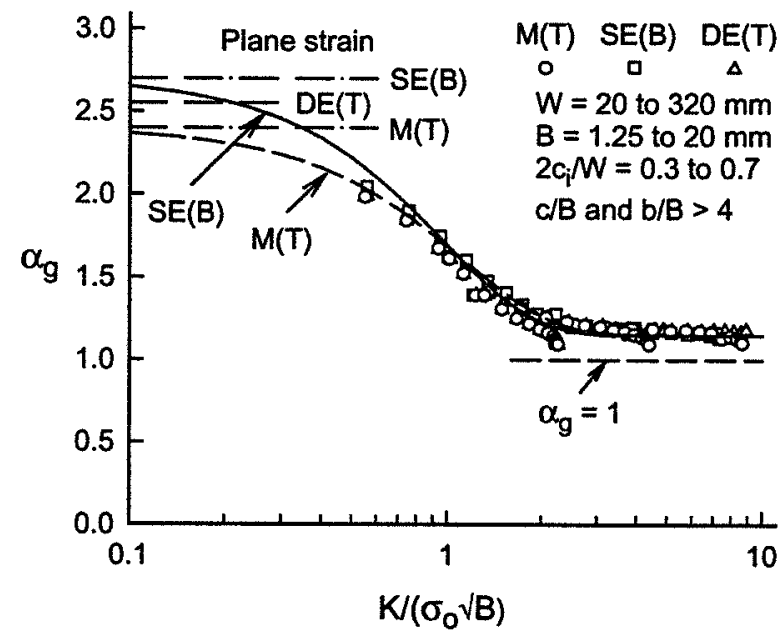

Fig. 11 - Global constraint factor for various specimens with $\mathrm{c} / \mathrm{B}$ and $\mathrm{b} / \mathrm{B}$ greater than 4 .

The test specimens shown in Fig. 3 had c/B and $\mathrm{b} / \mathrm{B}$ ratios greater than or equal to 4 . Thus, these specimens had the same global constraint factor for a given applied stress-intensity factor (or plastic-zone size to thickness ratio), which may explain why they developed the same critical CTOA values.

For $c / B$ and $b / B$ ratios less than 4 , the global constraint factors were found to be a function of specimen type, loading, thickness and width; and they were not uniquely related to the normalized stressintensity factor. Thus, for $\mathrm{c} / \mathrm{B}$ and $\mathrm{b} / \mathrm{B}$ less than 4 , the critical CTOA values may be a function of specimen type, with the $C(T)$ specimen having a higher constraint factor than the $M(T)$ specimen and resulting in a lower critical CTOA value.
The critical CTOA is a function of constraint and, thus, a function of absolute material thickness, similar to other fracture parameters. Figure 12 shows the critical CTOA values calculated for sheet and plate 2024 aluminum alloys from several studies. The open symbols are from as-rolled sheets or plates, and the solid symbols are from specimens machined from the 25-mm thick plate ${ }^{21}$. The CTOA values were determined by matching the failure loads on $C(T)$ specimens using the ZIP3D code. For both materials, larger thicknesses, generally, produce lower CTOA values. The T351 temper tended to produce higher CTOA values than the T3 temper. But the machined (T351) specimens tended to approach the as-rolled sheet material at thinner gages. It is suspected that the machining operation is removing surface material from the rolled plate that was contributing to the fracture behavior.

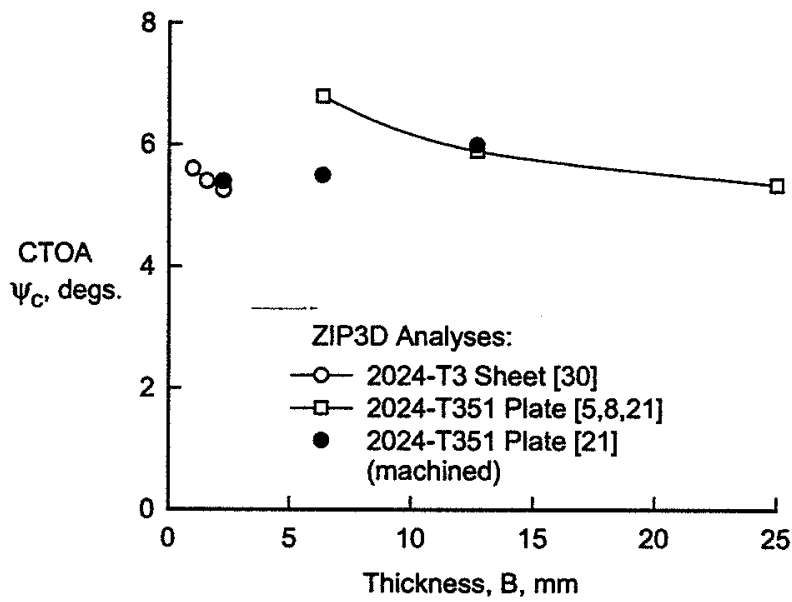

Fig. 12 - Calculated critical CTOA values for various material thicknesses.

\section{Discussion}

The results presented here tend to support the concept of a "constant" critical CTOA value for a given material, product form, and test environment, if the crack-length-to-thickness $(\mathrm{c} / \mathrm{B})$ ratio and the uncrackedligament-to-thickness $(\mathrm{b} / \mathrm{B})$ ratio is greater than or equal to about 4 . The non-constant values of CTOA, from previous analyses, have been traced to the use of inappropriate state-of-stress assumptions and severe crack tunneling in the aluminum alloy materials. Planestress (or plane-strain) behavior is inadequate when determining the critical CTOA values to fit loadagainst-remote-displacement behavior. Either 2-D analyses with the plane-strain core or 3-D analyses are required to match the local constraint behavior at the crack front and the large-scale (plane-stress) plastic deformations away from the crack front. 
Severe crack tunneling voids the use of loadagainst-(surface)-crack-extension values for thin-sheet aluminum alloys. Because free surface crack-extension values under estimate the true damage growth, fictitious CTOA values are calculated to fit the results. An "effective" crack extension value needs to be measured, such as the unloading compliance values or the areaaverage crack-extension values.

Figure 13 shows the trends in calculated critical CTOA values from the early 1980 's using plane-stress (or plane-strain) finite-element codes and the use of inappropriate surface crack-extension values. The "constant" CTOA concept in the 1990's was an engineering approach to correlate fracture data on different specimen types and to use these CTOA values to predict the residual strength of some very complex structural crack configurations ${ }^{30}$. Extensive CTOA measurements (e.g., Refs. 10,20,21) show that surface values approach nearly a constant value after a small

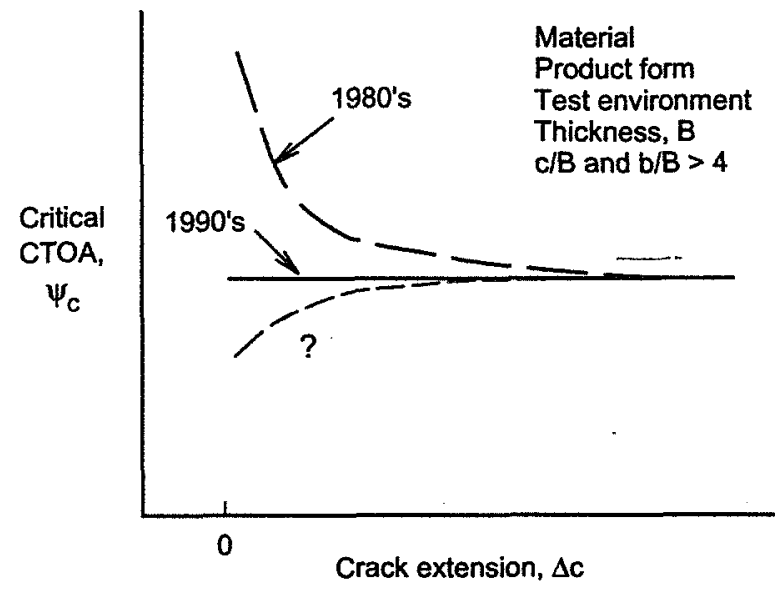

Fig. 13 - Trends in calculated critical CTOA values for a given material thickness.

amount of crack extension. The region of non-constant CTOA values (Figs. 3 and 4) appear to be related to thickness, but the region became smaller with larger thicknesses in the aluminum alloys. The studies on crack-front constraint also suggest that the critical CTOA values for the interior of a cracked specimen or structural component may be low because of the high (plane-strain) constraint, as shown in Fig. 8 and the lower dash curve in Fig. 13. Lloyd and Piascik ${ }^{31}$ have used the microtopography technique to measure the CTOA values in the interior of a thin-sheet aluminum alloy specimen and found slightly increasing CTOA values from 4 to 5 degrees over the crack extension range of 0.4 to $2 \mathrm{~mm}$. Further research is needed to measure the critical CTOA values in the interior of cracked specimens to obtain more conclusive evidence.
The results presented here also suggest that the local $\delta_{5}$-displacement measurements may be used to determine CTOA values as a function of crack extension for a given material thickness to access whether or not the critical CTOA is constant.

In practice, the critical CTOA values need to be determined for various specimen configurations, crack lengths, and thicknesses; and calculations need to be preformed using 3-D analyses to compute the global constraint factors. Plotting these values would then produce a critical-CTOA-against-constraint $\left(\alpha_{g}\right)$ plot, as shown in Fig. 14. For the same crack length, large thicknesses develop higher constraint factors around the crack front and produce a lower critical CTOA value. This concept is very similar to the J-integral-T-stress plot of Betegon and Hancock ${ }^{32}$, except that the fracture and constraint parameters are different. In the past, the T-stress (an in-plane constraint term) has been studied to assess its effect on the J-integral fracture toughness. The global constraint factor is a three-dimensional constraint factor that accounts for both in-plane and through-the-thickness normal stress effects on yielding. A curve such as that shown in Fig. 14 would characterize the CTOA toughness for a material, product form, and test environment. This relation could then be used to predict fracture of various specimen sizes that violate the $c / B$ and $b / B>4$ criteria. Again, further research is needed to evaluate this concept.

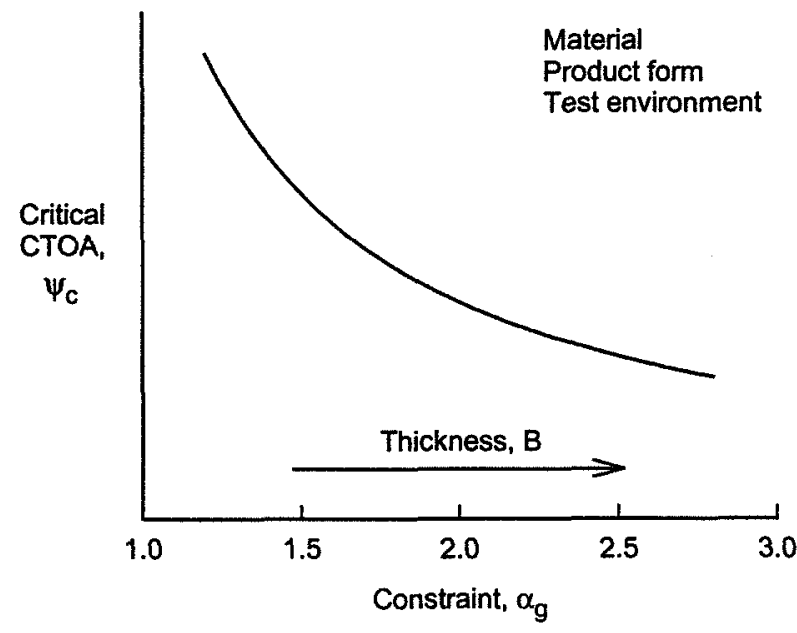

Fig. 14 - Critical CTOA against constraint relation-ship for a material, product form, and test environment.

\section{Concluding Remarks}

This paper reviewed the CTOA/CTOD fracture criterion and the use of the finite-element method to simulate fracture. Fracture results, measurements and analyses on aluminum alloys have supported the use of a "constant" CTOA value from initiation to failure. 
Constraint effects and crack tunneling were shown to be key issues in explaining why the CTOA criterion worked so well. The "constant" CTOA concept has been successfully used to predict the residual strength of some very complex structural crack configurations from laboratory specimens. Further CTOA measurements, such as microtopography, and finite-element analyses need to be made on other materials and thicknesses to evaluate the "constant" CTOA fracture criterion.

\section{References}

1. Andersson, H., "A Finite-Element Representation of Stable Crack Growth," Journal of Mechanics and Physics of Solids, Vol. 21, 1973, pp. 337-356.

2. de Koning, A. U., "A Contribution to the Analysis of Slow Stable Crack Growth," National Aerospace Laboratory Report NLR MP 75035U, 1975.

3. Shih, C F., de Lorenzi, H. G. and Andrews, W. R., "Studies on Crack Initiation and Stable Crack Growth," ASTM STP 668, 1979, pp. 65-120.

4. Kanninen, M. F., Rybicki, E. F., Stonesifer, R. B., Broek, D., Rosenfield, A. R. and Nalin, G. T., "ElasticPlastic Fracture Mechanics for Two-Dimensional Stable Crack Growth and Instability Problems," ASTM STP 668,1979 , pp. 121-150.

5. Newman, J. C., Jr, “An Elastic-Plastic Finite Element Analysis of Crack Initiation, Stable Crack Growth, and Instability," ASTM STP 833, 1984, pp. 93-117.

6. Brocks, W. and Yuan, H., "Numerical Studies on Stable Crack Growth," Defect Assessment in Components - Fundamentals and Applications, ESIS Pub. 9, 1991, pp. 19-33.

7. Newman, J. C., Jr., Shivakumar, K. N. and McCabe, D. E., "Finite Element Fracture Simulation of A533B Steel Sheet Specimens," Defect Assessment in Components - Fundamentals and Applications, ESIS Pub. 9, 1991, pp. 117-126.

8. James, M. A., Newman, J. C., Jr. and Johnston, W. M., Jr., "Three-Dimensional Analyses of Crack-TipOpening Angles and $\delta_{5}$-Resistance Curves for 2024T351 Aluminum Alloy," ASTM STP 1406, 2001.

9. Newman, J. C., Jr., Booth, B. C. and Shivakumar, K. N., "An Elastic-Plastic Finite-Element Analysis of the JResistance Curve using a CTOD Criterion," ASTM STP 945, 1988, pp. 665-685.
10. Newman, J. C., Jr., Dawicke, D. S. and Bigelow, C. A., "Finite-Element Analyses and Fracture Simulation in Thin-Sheet Aluminum Alloy," Durability of Metal Aircraft Structures, W.H. Wolfe Associates, Georgia, 1992, pp. 167-186.

11. Dawicke, D. S., Newman, J. C., Jr. and Bigelow, C. A., "Three-Dimensional CTOA and Constraint Effects during Stable Tearing in a Thin-Sheet Material," ASTM STP 1256, 1995, pp. 223-242.

12. Dawicke, D. S. and Newman, J. C., Jr., "Residual Strength Predictions for Multiple-Site Damage using a Three-Dimensional Finite-Element Analysis and a CTOA Criterion," ASTM STP 1332, 1999, pp. 815829.

13. Gullerud, A. S., Dodds, R. H., Jr., Hampton, R. W. and Dawicke, D. S., "Three-Dimensional Modeling of Ductile Crack Growth in Thin Sheet Metals: Computational Aspects and Validation," Engineering Fracture Mechanics, Vol. 63, 1999, pp. 347-374.

14. Young, R. D., Rouse, M., Ambur, D. R. and Starnes, J. H., Jr., "Residual Strength Pressure Tests and Nonlinear Analyses of Stringer- and FrameStiffened Aluminum Fuselage Panels with Longitudinal Cracks," NASA CP 208982, Part 2, 1999, pp. 408-426.

15. Seshadri, B. S., Newman, J. C., Jr., Dawicke, D. S. and Young, R. D., "Fracture Analysis of the FAA/NASA Wide Stiffened Panels," NASA CP 208982, Part 2, 1999, pp. 513-524.

16. Kobayashi, A. S., Emery, A. F., Love, W. J., Chao, Y.-H., and Johanson, O., "Dutile Crack Bifurcation and Arrest in Pressurized Pipe,” ASTM STP 969, 1988, pp. 441-465.

17. Luxmoore, A., Light, M. F. and Evans, W. T., "A Comparison of Energy Release Rates, the J-Integral and Crack Tip Displacements," International of Journal of Fracture, Vol. 13, 1977, pp. 257-259.

18. Paleebut, S., "CTOD and COD Measurements on Compact Tension Specimens of Different Thicknesses," M.S. thesis, Michigan State University, East Lansing, Michigan, 1978.

19. Reuter, W. G., Graham, S. M., Lloyd, W. R. and Williamson, R. L., "Ability of Using Experimental Measurements of CTOD to Predict Crack Initiation for Structural Components," Defect Assessment in Components - Fundamentals and Applications, ESIS Pub. 9, 1991, pp. 175-188. 
20. Dawicke, D. S. and Sutton, M. A., "CTOA and Crack Tunneling Measurements in Thin Sheet 2024-T3 Aluminum Alloy," Experimental Mechanics, Vol. 34, No. 4, 1994, p. 357.

21. Mahmoud, S. and Lease, K. B., "Effect of Specimen Thickness on the Characterization of CTOA in 2024T351 Aluminium Alloy," submitted to Engineering Fracture Mechanics, July 2000.

22. Dawicke, D. S., Sutton, M. A., Newman, J. C., Jr. and Bigelow, C. A., "Measurement and Analysis of Critical CTOA for an Aluminum Alloy Sheet," ASTM STP 1220, 1999, pp. 358-379

23. Rankin, C. C., Brogan, F. A., Loden, W. A. and Cabiness, H. D., "STAGS User Manual - Version 2.4," Lockheed-Martin Advanced Technology Center, Report LMSC P032594, 1997.

24. Eichenberger, T. W., "Fracture Resistance Data Summary," Report DA-20947, The Boeing Company, June 1992.

25. Shivakumar, K. N. and Newman, J. C., Jr., "ZIP3D - An Elastic and Elastic-Plastic Finite-Element Analysis Program for Cracked Bodies," NASA TM 102753, 1990.

26. James, M. A., "Residual Strength Calculations for Single and Multiple-Site Damage Cracks," First Joint DoD/FAA/NASA Conference on Aging Aircraft, July 1997, pp. 1789-1802.

27. James, M. A. and Newman, J. C., Jr., "Importance of Crack Tunneling during Fracture: Experiments and CTOA Analyses," $10^{\text {th }}$ International Congress of Fracture, Honolulu, Hawaii, December 3-7, 2001.

28. Koppenhoefer, K. C., Gullerud, A. S., Ruggieri, C. and Dodds, R. H., Jr., "WARP3D: Dynamic Nonlinear Analysis of Solids using a Preconditioned Conjugate Gradient Software Architecture," Structural Research Series 596, UILU-ENG-94-2017, University of Illinois, 1994.

29. Newman, J. C., Jr., Crews, J. H., Jr., Bigelow, C. A. and Dawicke, D. S., "Variations of a Global Constraint Factor in Cracked Bodies under Tension and Bending Loads," ASTM STP 1244, 1995, pp. 21-42.

30. Dawicke, D. S., Newman, J. C., Jr., Starnes, J. H., Jr., Rose, C. A., Young, R. D. and Seshadri, B. R., "Residual Strength Analysis Methodology: Laboratory Coupons to Structural Components," Third Joint FAA
DoD/NASA Aging Aircraft Conference, Albuquerque, NM, September 20-23, 1999.

31. Lloyd, W. R. and Piascik, R. S., "ThreeDimensional Crack Growth Assessment by Microtopographic Examination," ASTM STP 1256, 1995, pp. 303-318.

32. Betegon, C. and Hancock, J. W., "Two-Parameter Characterized of Elastic-PlasticCrack-Tip Fields," Journal of Applied Mechanics, Vol. 58, 1991, pp. 104110. 